This is the peer reviewed version of the following article: International Journal of Food Science and Technology, Volume54, Issue8, Pages 2520-2528, which has been published in final form at https://doi.org/10.1111/ijfs.14162. This article may be used for non-commercial purposes in accordance with Wiley Terms and Conditions for Self-Archiving.

\title{
Effects of the drying method on the oxidative stability of the free and encapsulated fractions of microencapsulated sunflower oil
}

Francisca Holgado, ${ }^{1}$ Gloria Márquez-Ruiz, ${ }^{1}$ M. Victoria Ruiz-Méndez,${ }^{2}$ and Joaquín Velasco ${ }^{2, *}$

${ }^{1}$ Instituto de Ciencia y Tecnología de Alimentos y Nutrición, Consejo Superior de Investigaciones Científicas (CSIC), c/ José Antonio Novais, 10, E-28040 Madrid, Spain

${ }^{1}$ Instituto de la Grasa, Consejo Superior de Investigaciones Científicas (CSIC), Campus Universidad Pablo de Olavide, Ctra. de Utrera Km 1, E-41013 Sevilla, Spain

*To whom correspondence should be addressed:

Telephone: $\quad+34954611550$

Fax: $\quad+34954616790$

E-mail: jvelasco@ig.csic.es 


\section{Summary}

The influence of the drying method, freeze-drying and spray-drying, on the oxidative stability of microencapsulated sunflower oil depended on the type of encapsulation matrix. For a dairytype matrix, formed by sodium caseinate and lactose, greater losses of tocopherols were detected during spray-drying, but both the free and encapsulated oil fractions were more stable against lipid oxidation than their freeze-dried counterparts. Results suggested that the free oil was also constituted by droplets that preserved their interfacial membrane and were protected by the matrix. Therefore, the free oil was not necessarily the non-encapsulated fraction. For a matrix constituted by gelatine, maltodextrin and sucrose, the emulsion showed low stability and a great destabilization during spray-drying. No significant effect of the drying method on the oxidative stability of the encapsulated fraction was found with this matrix, but the free oil of the spray-dried sample oxidised faster, probably due to the emulsion destabilization observed, which gave rise to a great amount of oil on the particle surface as a consequence of large droplets poorly stabilised.

Keywords: Microencapsulation, microencapsulated oil, free oil, spray-drying, freeze-drying, oxidation 


\section{Introduction}

Microencapsulation of oils in proteins and/or carbohydrates is a technological strategy to protect oils against oxidation. A few examples of oils microencapsulated in the food industry are functional food lipids such as fish oils and concentrates of long-chain polyunsaturated fatty acids, and oils as carriers of flavours, vitamins and others (Drusch \& Manino, 2009; Ghnimi et al., 2017; Bakry et al., 2016; Ruiz-Ruiz et al., 2017). The microencapsulation process is normally carried out in two steps. First, the oil is emulsified in an aqueous medium containing the encapsulating components. Then, the emulsion is dried, normally by spray-drying, to obtain a powder product where the oil in a disperse phase is entrapped or encapsulated in the inner of solid particles. The encapsulation matrix acts as a physical barrier to oxygen, slowing down the oxidative process.

Freeze-drying is one of the drying methods more recommended for lipids highly susceptible to oxidation due to the low temperature at which the process is carried out and also because the drying is performed at vacuum conditions. However, it is a very expensive technology, associated with high investment, high energy consumption and long processing time (Fang \& Bhandari, 2012). Another disadvantage of the process is the open porous structure of the final product, which makes it be exposed to the air.

Spray-drying is a simple, inexpensive method that uses high temperatures for the drying of emulsions during a very short time. Compared to freeze-drying, greater losses of tocopherols have been observed as a consequence of the high temperatures (Ogrodowska et al., 2017). Likewise, presumably greater initial oxidation due to the process conditions may result in less oil oxidative stability.

Studies in which the spray-drying and freeze-drying methods are compared in terms of how they affect the oil oxidative stability of dried microencapsulated oils are not numerous. A few showed that spray-dried (SD) samples were more stable against oxidation than freeze-dried 
(FD) samples, which was attributed to less porosity of the matrix and less free oil content (Eratte et al., 2014; Cano-Higuita et al., 2015; Kaushik 2016, Ogrodowska et al., 2017). Other studies have also exhibited greater stability of SD in a few samples, but, depending on the matrix composition, the opposite was also found (Anwar \& Kunz, 2011). Other authors have not observed clear differences between the two drying methods (Karthik \& Anandharamakrishnan, 2013; González et al, 2016).

One of the main limitations of these studies is that only the total oil fraction was evaluated. When oxidation is initiated in the free oil fraction, the oxidation compounds are diluted with the non-altered oil in the extraction procedure (Márquez-Ruiz et al., 2003). This is probably the reason why the analysis of the total oil did not allow determining clearly which drying method produced samples with higher oxidative stability in the studies remarked above (Karthik \& Anandharamakrishnan, 2013; González et al, 2016).

The aim of this work was to study the influence of the drying method, freeze- and spray-drying, on the oxidative stability of microencapsulated sunflower oil, evaluating the free and encapsulated oil fractions separately. This analytical approach will allow determining the oxidation state in a more objective and precise way than when only the total oil fraction is evaluated. Two dried microencapsulated oil (DMO) samples prepared with different encapsulation components were studied. A dairy-like sample containing sodium caseinate and lactose, and another matrix formed by gelatine, as emulsifier, and sucrose and maltodextrin were examined. Both matrices were studied in a previous work because of their relatively high powder physical stability (Holgado et al., 2013),

\section{Materials and methods}

\section{Materials}

Conventional sunflower oil was used as study model. This was acquired from a local supermarket. D-lactose monohydrate, sodium caseinate, sucrose (99\%) and gelatine from 
bovine milk were purchased from Sigma Chemical Co. (St. Louis, MO). Maltodextrin 10 (dextrose equivalent of 10) was purchased from Fluka (Sigma-Aldrich Chemie Steinheim, Germany). All others chemicals used were of analytical grade.

\section{Oil microencapsulation}

The DMO samples were prepared in triplicate by freeze-drying or spray-drying of $\mathrm{o} / \mathrm{w}$ emulsions. The sample containing sodium caseinate (CAS sample) was prepared from an emulsion that comprised sunflower oil, sodium caseinate, lactose and water at a mass composition of 10:10:10:70, respectively. The sample containing maltodextrin (MD sample) was made from an o/w emulsion constituted by sunflower oil, sucrose, maltodextrin (DE 10), gelatine and water at a mass composition of 10:12:7:1:70, respectively. Both formulations were those studied in a previous work (Holgado et al., 2013). First, a coarse emulsion was prepared with a DI-25 Ultraturrax (IKA, Germany) by applying $454 \boldsymbol{g}(8,000 \mathrm{rpm})$ for $2 \mathrm{~min}, 641 \boldsymbol{g}$ $(9,500 \mathrm{rpm})$ for $2 \mathrm{~min}$ and $1294 \mathrm{~g}(13,500 \mathrm{rpm})$ for $1 \mathrm{~min}$. Then, the coarse emulsion was homogenised in an EmulsiFlex-C5 (Avestin Inc., Canada) high pressure homogeniser by applying $70 \mathrm{MPa}$ and one pass. Different batches of emulsions were prepared and mixed with gentle stirring. A portion of each emulsion was frozen at $-32{ }^{\circ} \mathrm{C}$ for $24 \mathrm{~h}$ and the rest was kept at $4{ }^{\circ} \mathrm{C}$ overnight.

The frozen emulsions were freeze-dried in a lab-scale Heto FD3 freeze-dryer (Allerød, Denmark) for $48 \mathrm{~h}$. In batches of $20 \mathrm{~g}$, the dried samples were ground in a domestic electronic coffee grinder of $400 \mathrm{~mL}$ volume using two operations of $5 \mathrm{~s}$ each.

The emulsions cooled at $4{ }^{\circ} \mathrm{C}$ were diluted at $50 \mathrm{wt} \%$ with water the following day and spraydried in a pilot-scale rotary disc atomizer (Anhydro, Copenhagen, Denmark). The disc operated at a rate of $16,000 \mathrm{rpm}$ and the emulsion feed flow was $7 \mathrm{~L} / \mathrm{h}$. The inlet and outlet air temperatures were $220^{\circ} \mathrm{C}$ and $90{ }^{\circ} \mathrm{C}$, respectively. 
Physicochemical properties of the samples

Microencapsulation efficiency (ME)

ME was measured according to a previous study (Holgado et al., 2013).

Oil droplet size

Analysis of oil droplet size was performed in the emulsions reconstituted in water at a weight ratio of 1:7 according to Holgado et al. (2013). A Malvern Mastersizer X (Malvern Instruments, Malvern, UK) operating with a $2 \mathrm{~mW} \mathrm{He}-\mathrm{Ne}$ laser beam $(\lambda=633 \mathrm{~nm})$ and a $45 \mathrm{~mm}$ lens (size range $0.05-80 \mu \mathrm{m}$ ) was used. A relative refractive index $\eta_{\text {oil }} / \eta_{\text {water }}$ of 1.095 and an absorption value of 0.1 were utilised in the calculations.

\section{Water activity}

The water activity of the samples was measured using a PawKit hygrometer (DECAGON, USA).

\section{Glass transition temperature}

The glass transition temperature (Tg) was determined using a DSC Q2000 calorimeter (TA Instruments, New Castle, DE, USA) according to Holgado et al. (2013).

\section{Storage conditions}

Independent 10-g samples of DMO were placed on Petri dishes and stored in desiccators in the dark at $30^{\circ} \mathrm{C}$. The desiccators contained silica gel to create a dry atmosphere and so favour oxidation. The relative humidity inside the desiccators was $0.0 \%$. As to the bulk oil, a 20 -g sample was placed into a $125-\mathrm{mL}$ beaker and this was stored in a desiccator at the same storage conditions as the DMOs. Periodic samplings were performed during a period of 100 days for the oil and 200 days for the DMOs. The samples were kept at $-25^{\circ} \mathrm{C}$ until analysis.

\section{Extraction of the free oil}

The free oil fraction was extracted with n-hexane as previously reported (Holgado et al., 2013). 


\section{Extraction of the encapsulated oil}

The encapsulated oil fraction was extracted from the samples devoid of free oil. The oil was released by the disruption of the matrix with a mortar and pestle and extracted with diethyl ether. Three milliliters of deionised water was added to $10 \mathrm{~g}$ of sample to form a kind of dough with the mortar. Then $5 \mathrm{~g}$ of anhydrous sodium sulphate was added to remove the water and mixed with the mortar until a granular mass was formed. The oil was subsequently extracted with three extractions of $70 \mathrm{~mL}$ diethyl ether each. The solvent was filtered through a filter paper containing anhydrous sodium sulphate and evaporated in a rotary evaporator at $40{ }^{\circ} \mathrm{C}$. The extracted oil was finally dried to constant weight using a stream of nitrogen.

Peroxide value $(P V)$

PV was determined by the standard iodometric titration method according to IUPAC Standard Method 2.501 (1992).

\section{Analysis of oxidation compounds}

The oxidation state was approached applying a method developed in our lab that combines solid-phase extraction (SPE) and high-performance size-exclusion chromatography (HPSEC) (Márquez-Ruiz et al., 1996). This enables the quantification of the total fraction of the nonvolatile oxidation products in three groups of compounds, i.e. triacylglycerol oligomers (TGO), triacylglycerol dimers (TGD) and oxidised triacylglycerol monomers (oxTGM). In addition, the hydrolysis compounds, DG and FFA, are also determined with this analysis. The sum of the oxidation and hydrolysis products constitutes the total fraction of polar compounds, called so because they have greater polarity than the non-altered triacylglycerols. The total fraction of polar compounds were isolated by SPE and analysed by HPSEC, as described elsewhere (Velasco et al., 2006). 
Analysis of triacylglycerol polymers

Polymers were measured by direct HPSEC analysis of the oil extracts according to IUPAC standard method 2.508 (1992).

Analysis of tocopherol

Tocopherols were determined by normal-phase HPLC with fluorescence detection according to IUPAC Standard Method 2.411 (1992).

\section{Statistical analysis}

Analytical determinations were performed in triplicate and results were expressed as mean values followed by the standard deviation. Multiple comparisons between means were made by one-factor ANOVA applying Tukey's test in 24.0 SPSS Statistics program (SPSS Inc., Chicago, IL, USA). Linear regression analysis was applied in Microsoft Excel 2010 (Microsoft Corporation, Redmond, WA, USA) to determine correlations between the PV and the oxTGM contents. Significance was established at $p<0.05$.

\section{Results and discussion}

\section{Physicochemical characterisation of the DMO samples}

The drying method had a significant influence on the ME in the CAS sample, whereas no significant effect was found in the MD sample (Table 1), as previously reported (Holgado et al., 2013). As expected, the ME was far higher in the SD-CAS sample (94\%) compared to the FD product (61\%). The lower ME of FD samples compared to SD emulsions has been attributed to a greater particle porosity of the former (Sims, 1994), which enables a greater solvent penetration in the extraction of the free oil (Drusch \& Berg, 2008). The ME results obtained in the MD samples were in agreement with studies carried out by Desobry et al. (1997), who found similar values for FD (65\%) and SD (62\%) samples of an emulsion containing $25 \mathrm{DE}$ maltodextrin. 
The oil droplet size measured in reconstituted emulsions showed that the oil phase of the CAS emulsions preserved to a great extent its physical structure during the drying methods (Table 1). Only a very slight increase in the droplet size appeared to occur as a consequence of the freeze-drying. In both cases, the reconstituted emulsions presented very small droplets with a unimodal size distribution confined in a very narrow size range. On the other hand, the results obtained in the MD emulsions were indicative of poor emulsion stability, as previously reported (Holgado et al., 2013). The reconstituted MD emulsions presented a bimodal size distribution (not shown) in a very wide size range. The SD sample showed a great emulsion destabilisation, presenting larger oil droplets distributed in a much wider size range compared to its FD homolog.

The SD samples showed substantially higher $\mathrm{a}_{\mathrm{w}}$ values than their counterpart FD samples. The $T_{g}$ values were lower for the SD products in both types of sample, which can be attributed to their greater $\mathrm{a}_{\mathrm{w}}$ values. The higher $\mathrm{T}_{\mathrm{g}}$ values found for the CAS samples were indicative of a greater powder structure stability. Accordingly, the CAS samples did not show structural changes that gave rise to changes in the oil distribution during the whole oxidation assay (200 d), as the ME remained unchanged. On the other hand, the MD samples presented a significant increase of the ME up to $95 \%$ from $100 \mathrm{~d}$ of storage and this remained constant afterwards. Increased ME during storage has also found in other studies and this was attributed to losses of porosity due to the collapse of the particle structure (Ponginebbi et al., 2000; Hardas et al., 2002).

\section{Oxidation state of the initial DMO samples}

Results for analytical parameters indicative of the oxidation state of the oils extracted from the DMO samples are listed in Table 2. For comparative purposes, those for the initial oil have also been included. The oil showed oxidation and hydrolysis levels commonly found in refined oils (Márquez-Ruiz \& Dobarganes, 2005). The determination of polar compounds did not show 
significant differences between the oil and the oil extracts. However, incipient oxidation was detected in the DMOs by the PV. The PV was slightly higher in the extracts compared to the initial oil, especially those of the free oil fractions of the MD samples. No clear differences in the PV were found between the FD and SD initial samples. The PVs of the free and encapsulated oil fractions of the FD-MD samples were, respectively, significantly higher compared to their SD-MD counterparts, whereas no significant differences were found in the CAS samples. Significant losses of tocopherols were also detected in all the extracts compared to the initial oil. Greater losses were detected in the SD-CAS sample compared to its FD homolog, whereas no significant differences were found in the MD samples. In addition, the tocopherol losses for the MD samples were greater in the free oil than in the encapsulated oil fraction, which was consistent with the slightly higher oxidation denoted by the PV.

\section{Oxidation of the bulk oil}

The oxidation of the sunflower oil used in the preparation of the DMO samples was also examined. Results for different parameters indicative of oxidative changes are listed in Table 3. According to previous studies (Martín-Polvillo et al., 2004; Velasco et al., 2006), polymerisation was very low in the presence of tocopherols and the group of oxTGM rose progressively along with the PV. When tocopherols were exhausted, oxidation accelerated and polymers substantially increased. The total loss of tocopherols and polymerisation marked the end of the induction period. At this oxidation extent, oxidative rancidity was patently perceived. Confirming previous studies (Velasco et al., 2006), the contents of oxTGM and the PV showed a good linear correlation $\left(\mathrm{r}^{2}=0.996 ;\right.$ oxTGM] $(\mathrm{wt} \%)=0.58( \pm 0.09)+0.046( \pm 0.001) \mathrm{PV}$ $(\mathrm{meq} / \mathrm{kg}))$ during the induction period. Therefore both analytical determinations can be used alternatively when oils are protected by their naturally occurring antioxidants.

Although oxidative rancidity was with no doubts perceived when the oil became unprotected of its natural antioxidants, this was and normally is perceptible at much lower oxidation levels, 
when the concentrations of volatile oxidation products are greater than the sensory perception thresholds. Generally, oils or foods containing oils subjected to room or moderate temperature do not normally reach global oxidation levels greater than $5 \%$ on oil (w/w) because at these levels rancidity is definitely perceived (Velasco et al., 2010).

\section{Oxidation of the DMO samples}

Oxidation in the DMOs was evaluated by determining the PV, the contents of triacylglycerol polymers and the loss of tocopherols (Figure 1). Confirming previous studies on freeze-dried microencapsulated oils (Velasco et al., 2006; 2009a; Morales et al., 2015), the free oil fractions of both the FD and SD samples showed a similar oxidative pattern to that described above for the bulk oil, whereas the oxidation in the encapsulated fraction took place in a discontinuous way. A definite induction period whose end was marked by the total loss of tocopherols, a substantial increase of polymers and high PV was detected in the free oil (Figure 1). In contrast, the encapsulated oil presented relatively high contents of compounds of advanced oxidation, i.e. polymers, when the levels of tocopherols were still considerable. This fact was indicative of oil droplets oxidising at different rate and the discontinuous nature of oxidation in these products where the oil constitutes a disperse phase (Velasco et al., 2006; 2009a; Morales et al., 2015). Thus the encapsulated fraction comprised oil droplets with different oxidation states, including droplets that were well-protected by the matrix, i.e. with low oxidation and with still substantial contents of tocopherols, and droplets in advanced oxidation stages, i.e. with no tocopherols and high polymerization. Therefore, these results showed that both FD and SD microencapsulated oils presented similar oxidation patterns.

Unlike the SD sample, the global oxidation of the encapsulated fraction of the FD-CAS sample was slightly faster compared to the free oil fraction. In this regard, the PV increased slightly faster since the first stages of oxidation (Figure 1a). This was not the case of the MD samples, in which the matrix clearly protected the encapsulated fraction (Figure 1a'). The differences in 
the global oxidation rate between the free and encapsulated oil fractions depend on a number of factors, including the rate of oxygen diffusion throughout the matrix. If the oxidation reaction is slower than the diffusion of oxygen, the latter stops being rate-controlling (Velasco et al., 2009b).

As drawn from the content of polymers and the total loss of tocopherol (Figure 1b-c), the free oil fraction reached the induction period earlier in the SD-CAS sample (105-117 d) than in the FD-CAS sample (131-145 d), whereas tocopherol in the encapsulated fraction was exhausted earlier in the FD sample (145-153 d) than in the SD sample (190-200 d). As to the MD samples, the drying method did not seem to cause a significant effect on the oxidative stability of the free and encapsulated oil fractions (Figure 1a'-c').

When the antioxidants are completely lost, the level of oxidation is however rather high in terms of rancidity perception. From a practical point of view, it is more appropriate to examine the oxidative development during the first stages of the process rather than at the end of the induction period. Considering that oils and foods subjected to low temperatures rarely reach levels of oxidation greater than $5 \%$ on oil (w/w) (Velasco et al., 2010), a PV of $100 \mathrm{meq} / \mathrm{kg}$ could be established as a maximum limit. Assuming an average molecular weight of 900 for hydroperoxides, this limit corresponds to $4.5 \%$ oxTGM on oil (w/w).

When the PV increased up to $100 \mathrm{meq} / \mathrm{kg}$, the increment in the polymer content of the encapsulated oil fractions was not higher than $1 \%$ on oil $(w / w)$ in the four samples studied. Such level of polymerization has also been detected at the end of the induction period of vegetable oils subjected to room or moderate temperatures in different studies (Martín-Polvillo et al., 2004; Morales et al., 2014). Therefore, at levels up to $100 \mathrm{meq} / \mathrm{kg}$, the PV appears to be a useful measure to evaluate the oxidation of both the free and encapsulated oil fractions. Table 4 lists the time at which the PV reached such a limit in the different oil fractions and this is compared to the time when tocopherols were completely lost. The results showed that during 
the early stages the oxidation was slower in the SD-CAS sample compared to its FD counterpart, in both oil fractions. Regarding the MD samples, early oxidation was faster in the free oil of the SD sample and similar results were obtained for the encapsulated fractions (49$59 \mathrm{~d})$.

The greater oxidative stability of the SD-CAS sample compared to its FD counterpart was in agreement with most studies in which both drying methods were compared and only the total oil fraction was analysed (Eratte et al., 2014; Cano-Higuita et al., 2015; Kaushik 2016, Ogrodowska et al., 2017). In these studies the less oxidative stability of the freeze-dried samples was attributed to their more porous structure and greater free oil content. However, in the present work, the free oil fraction was also more stable in the SD sample. This fact could be related to a less surface oil content in the SD sample. Although the free oil fraction is mainly constituted by discrete deposits of oil on the surface of the particles, individual oil droplets preserving their interfacial membrane that are close to the surface are also accessible to the organic solvent during the free oil extraction, especially when the surface oil is first removed (Drusch \& Berg, 2008, Holgado et al., 2013). The protection of these droplets that also contribute to the free oil fraction could justify the slower global oxidation of the free oil in the SD sample compared to its FD homolog.

It is worth noting that the drying method did not exert a significant effect on the oxidative stability of the encapsulated oil fraction in the MD sample, although it did on the free oil. This fact definitely indicates that the influence of the drying method on the oil stability depends on a great extent on the encapsulation matrix used. The fast oxidation of the free oil in the SD-MD sample would not have been detected if only the total oil had been analysed and so the differences found between the SD and FD samples would not have been noted, since the encapsulated oil constitutes the majority oil fraction. Unlike the CAS samples, the MD emulsions presented very low stability. In fact, the oil droplet size increased considerably when 
the emulsion was spray-dried (Table 1). The fast oxidation of the free oil could be related to such an emulsion destabilization. In this regard, the free oil could have been constituted by a great amount of discrete oil deposits on the particle surface, highly expose to oxygen, and, to a lower extent, by oil droplets protected by the interfacial membrane. It has been reported that large oil droplets poorly stabilized tend to increase the amount of surface oil (Anwar \& Kunz, 2011). This would also explain the lower stability of the free fractions in the MD samples when compared to the CAS samples. Unlike the MD samples, the reconstituted CAS emulsions presented much smaller and more uniform oil droplets, indicating a great preservation of the interfacial membrane during the microencapsulation process.

\section{Conclusions}

The influence of the drying method on the oil oxidative stability of microencapsulated sunflower oil depended on the type of encapsulation matrix used. For the matrix prepared with sodium caseinate and lactose, the emulsion was quite stable and presented small and homogeneous oil droplet sizes after the drying by the two processes applied. Greater losses of tocopherols were observed as a consequence of the spray-drying. Both the free and encapsulated oil fractions of the spray-dried sample were more stable against lipid oxidation than their freezedried counterparts. Therefore, the higher oxidative stability of the spray-dried sample was not only due to lower particle porosity and less free oil content. Results suggested that a good part of the free oil was constituted by droplets that preserved their interfacial membrane and were protected by the encapsulation wall. Consequently, the free oil was not necessarily indicative of the non-encapsulated oil fraction. For the samples containing gelatine, maltodextrin and sucrose, the emulsion presented low stability and a great destabilization was observed as a result of the spray-drying. Even so, the microencapsulation efficiency was not low, but it was not significantly different from that of the freeze-dried sample. The expected greater losses of tocopherols in the spray-dried sample were not observed. No significant effect of the drying 
method on the oil stability of the encapsulated fraction was found, but the free oil of the spraydried sample oxidised more rapidly. This fact could be attributed to the emulsion destabilization observed, giving rise to a great amount of oil on the particle surface as a consequence of large droplets poorly stabilised.

\section{Acknowledgements}

This work was funded by the Spanish Ministry of Economy, Industry and Competitiveness through project AGL2013-45110-R. The authors thank Irene Pérez de la Rosa for technical assistance.

\section{Conflict of interest}

The authors declare that there are no conflicts of interest regarding the research, authorship or publication of this article. 


\section{References}

Anwar, S.H. \& Kunz, B. (2011). The influence of drying methods on the stabilization of fish oil microcapsules: Comparison of spray granulation, spray drying, and freeze drying. Journal of Food Engineering, 105, 367-378.

Bakry, A. M., Abbas, S., Ali, B., Majeed, H., Abouelwafa, M. Y., Mousa, A. \& Liang, L. (2016). Microencapsulation of oils: A comprehensive review of benefits, techniques, and applications. Comprehensive Reviews in Food Science and Food Safety, 15, 143 182.

Cano-Higuita, D. M., Malacrida, C. R. \& Telis, V. R. N. (2015). Stability of curcumin microencapsulated by spray and freeze drying in binary and ternary matrices of maltodextrin, gum arabic and modified starch. Journal of Food Processing and Preservation, 39, 2049-2060.

Desobry, S.A., Netto, F.M. \& Labuza, T.P. (1997). Comparison of spray-drying, drum-drying and freeze-drying for $\beta$-carotene encapsulation and preservation. Journal of Food Science, 62, 1158-1162.

Drusch, S. \& Berg, S. (2008). Extractable oil in microcapsules prepared by spray-drying: Localisation, determination and impact on oxidative stability. Food Chemistry, 109, 17-24.

Drusch, S. \& Mannino, S. (2009). Patent-based review on industrial approaches for the microencapsulation of oils rich in polyunsaturated fatty acids. Trends in Food Science \& Technology, 20, 237-244.

Eratte, D., Wang, B., Dowling, K., Barrow, C. J. \& Adhikari, B. P. (2014). Complex coacervation with whey protein isolate and gum Arabic for the microencapsulation of omega-3 rich tuna oil. Food \& Function, 5, 2743-2750.

Fang, Z. \& Bhandari, B. (2012). Spray drying, freeze drying and related processes for food ingredient and nutraceutical encapsulation. In: Encapsulation Technologies and Delivery Systems for Food Ingredients and Nutraceuticals (edited by N. Garti and D.J. McClements). Pp. 73-109. Cambridge, UK: Woodhead Publishing. 
Ghnimi, S., Budilarto, E. \& Kamal-Eldin, A. (2017). The New Paradigm for Lipid Oxidation and Insights to Microencapsulation of Omega-3 Fatty Acids. Comprehensive Reviews in Food Science and Food Safety, 16, 1206-1218.

González, A., Martínez, M.L., Paredes, A. J., León, A.E. \& Ribotta, P.D. (2016). Study of the preparation process and variation of Wall components in chia (Salvia hispanica L.) oil microencapsulation. Powder Technology, 301, 868-875.

Hardas, N., Danviriyakul, S., Foley, J. L., Nawar, W. W. \& Chinachoti, P. (2002). Effect of relative humidity on the oxidative and physical stability of encapsulated milk fat. Journal of the American Oil Chemists Society, 79, 151-158.

Holgado, F., Márquez-Ruiz, G., Dobarganes, C. \& Velasco, J. (2013). Influence of homogenisation conditions and drying method on physicochemical properties of dehydrated emulsions containing different solid components. International Journal of Food Science and Technology, 48, 1498-1508.

IUPAC (1992). Standard methods for the analysis of oils, fats and derivatives (7th ed.). Oxford: Blackell.

Karthik, P. \& Anandharamakrishnan, C. (2013) Microencapsulation of docosahexaenoic acid by spray-freeze-drying method and comparison of its stability with spray-drying and freeze-drying methods. Food and Bioprocess Technology, 6, 2780-2790.

Kaushik, P., Dowling, K., McKnight, S., Barrow, C. J. \& Adhikari, B. (2016) Microencapsulation of flaxseed oil in flaxseed protein and flaxseed gum complex coacervates. Food Research International, 86, 1-8.

Márquez-Ruiz, G. \& Dobarganes, M. C. (2005). Analysis of non-volatile lipid oxidation compounds by high-performance size-exclusion chromatography. In: Analysis of Lipid Oxidation (edited by A. Kamal-Eldin and J. Pokorny). Pp. 40-69. Champaign, USA: AOCS Press.

Márquez-Ruiz, G., Martín-Polvillo, M. \& Dobarganes, M. C. (1996). Rapid, quantitative determination of polar compounds in fats and oils by solid-phase extraction and sizeexclusion chromatography using monostearin as internal standard. Journal of Chromatography A, 749, 55-60. 
Márquez-Ruiz, G., Velasco, J. \& Dobarganes, C. (2003). Oxidation in dried microencapsulated oils. In: Lipid Oxidation Pathways (edited by A. Kamal-Eldin). Pp. 245-264. Champaign, USA: AOCS Press.

Martín-Polvillo, M., Márquez-Ruiz, G. \& Dobarganes, M. C. (2004). Oxidative stability of sunflower oils differing in unsaturation degree during long-term storage at room temperature. Journal of the American Oil Chemists Society, 81, 577-583.

Morales, A., Marmesat, S., Ruiz-Méndez, M. V., Márquez-Ruiz, G. \& Velasco, J. (2014). Formation of oxidation products in edible vegetable oils analyzed as FAME derivatives by HPLC-UV-ELSD. Food Research International, 62, 1080-1086.

Morales, A., Marmesat, S., Victoria Ruiz-Mendez, M., Marquez-Ruiz, G. \& Velasco, J. (2015). New analytical evidence of discontinuous oxidation in dried microencapsulated lipids. Journal of the American Oil Chemists Society, 92, 1601-1607.

Ogrodowska, D., Tanska, M. \& Brandt, W. (2017). The influence of drying process conditions on the physical properties, bioactive compounds and stability of encapsulated pumpkin seed oil. Food and Bioprocess Technology, 10, 1265-1280.

Ponginebbi, L., Nawar, W. W. \& Chinachoti, P. (2000). Effect of relative humidity on lipid oxidation in freeze-dried emulsions. Grasas y Aceites, 51, 348-354.

Ruiz-Ruiz, J. C., Ortiz-Vazquez, E. L. \& Segura-Campos, M. R. (2017). Encapsulation of vegetable oils as source of omega-3 fatty acids for enriched functional foods. Critical Reviews in Food Science and Nutrition, 57, 1423-1434.

Sims, R. J. (1994). Oxidation of fats in food products. INFORM, 5, 1020-1028.

Velasco, J., Holgado, F., Dobarganes, C. \& Marquez-Ruiz, G. (2009a). Influence of relative humidity on oxidation of the free and encapsulated oil fractions in freeze-dried microencapsulated oils. Food Research International, 42, 1492-1500.

Velasco, J., Dobarganes, C., Holgado, F. \& Marquez-Ruiz, G. (2009b). A follow-up oxidation study in dried microencapsulated oils under the accelerated conditions of the Rancimat test. Food Research International, 42, 56-62. 
Velasco, J., Dobarganes, C. \& Márquez-Ruiz, G. (2010). Oxidative rancidity in foods and food quality. In: Chemical Deterioration and Physical Instability of Foods and Beverages (edited by L. Skibsted, J. Risbo and M. Andersen). Pp. 3-32. Cambridge, UK: Woodhead Publishing Limited.

Velasco, J., Marmesat, S., Dobarganes, C. \& Marquez-Ruiz, G. (2006). Heterogeneous aspects of lipid oxidation in dried microencapsulated oils. Journal of Agricultural and Food Chemistry, 54, 1722-1729. 
Table 1 Physicochemical characteristics of the dried microencapsulated oil samples.

\begin{tabular}{lllll}
\hline & FD-CAS & SD-CAS & FD-MD & SD-MD \\
\hline ME $(\%)$ & $61.2 \pm 1.1 \mathrm{a}$ & $94.1 \pm 0.2 \mathrm{c}$ & $77.1 \pm 2.3 \mathrm{~b}$ & $80.1 \pm 0.3 \mathrm{~b}$ \\
Oil droplet size: & & & & \\
$\mathrm{d}_{(\mathrm{v}, 0.5)}(\mu \mathrm{m})$ & $0.85 \pm 0.02 \mathrm{~b}$ & $0.48 \pm 0.02 \mathrm{a}$ & $3.77 \pm 0.04 \mathrm{c}$ & $15.94 \pm 0.08 \mathrm{~d}$ \\
$\mathrm{~d}_{(\mathrm{v}, 0.9)-\mathrm{d}_{(\mathrm{v}, 0.1)}(\mu \mathrm{m})}$ & $3.47 \pm 0.06 \mathrm{~b}$ & $1.33 \pm 0.15 \mathrm{a}$ & $20.50 \pm 0.82 \mathrm{c}$ & $56.78 \pm 0.30 \mathrm{~d}$ \\
$\mathrm{~d}_{32}(\mu \mathrm{m})$ & $0.55 \pm 0.04 \mathrm{~b}$ & $0.40 \pm 0.05 \mathrm{a}$ & $1.48 \pm 0.02 \mathrm{c}$ & $1.76 \pm 0.01 \mathrm{~d}$ \\
$\mathrm{~A}_{\mathrm{N}}\left(\mu \mathrm{m}^{-1}\right)$ & $10.95 \pm 0.80 \mathrm{c}$ & $15.16 \pm 1.91 \mathrm{~d}$ & $4.05 \pm 0.05 \mathrm{~b}$ & $3.41 \pm 0.02 \mathrm{a}$ \\
Water activity & $0.06 \pm 0.00 \mathrm{~b}$ & $0.39 \pm 0.00 \mathrm{~d}$ & $0.04 \pm 0.00 \mathrm{a}$ & $0.25 \pm 0.00 \mathrm{c}$ \\
Glass Transition Temperature $\left({ }^{\circ} \mathrm{C}\right)$ & $61.5 \pm 0.3 \mathrm{~d}$ & $50.3 \pm 0.5 \mathrm{c}$ & $40.7 \pm 0.4 \mathrm{~b}$ & $37.8 \pm 0.4 \mathrm{a}$ \\
\hline
\end{tabular}

FD, samples prepared by freeze-drying; SD, samples prepared by spray-drying; CAS, samples containing sodium caseinate and lactose; MD, samples containing maltodextrin, sucrose and gelatine; ME, microencapsulation efficiency; $d$ (v, 0.5), mean droplet size; $\mathrm{d}_{(\mathrm{v}, 0.9)}-\mathrm{d}_{(\mathrm{v}, 0.1)}$, range of droplet sizes; $\mathrm{d}_{32}$, Sauter mean diameter; $\mathrm{A}_{\mathrm{N}}$, average surface area. Results are expressed as mean \pm standard deviation $(\mathrm{n}=3)$. Different letters for each determination denote significant differences $(P<0.05)$. 
Table 2 Characterization of the initial oil and the oils extracted from the initial dried microencapsulated oil samples.

\begin{tabular}{|c|c|c|c|c|c|c|c|}
\hline \multirow{2}{*}{ Sample } & \multirow{2}{*}{$\begin{array}{l}\text { Total } \\
\text { PC } \\
\text { (wt\% on oil) }\end{array}$} & \multicolumn{4}{|c|}{ PC distribution (wt \% on oil) } & \multirow{2}{*}{$\begin{array}{l}\mathrm{PV} \\
\left(\mathrm{meq} \mathrm{O}_{2} / \mathrm{kg}\right)\end{array}$} & \multirow{2}{*}{$\begin{array}{l}\text { Toc } \\
(\mathrm{mg} / \mathrm{kg})\end{array}$} \\
\hline & & TGO+TGD & oxTGM & DAG & FFA* & & \\
\hline Oil & $4.9 \pm 0.1 \mathrm{a}$ & $0.7 \pm 0.1 \mathrm{ab}$ & $2.4 \pm 0.1 \mathrm{ab}$ & $1.4 \pm 0.1 \mathrm{a}$ & $0.4 \pm 0.0 \mathrm{a}$ & $3.0 \pm 0.1 \mathrm{a}$ & $891 \pm 12 \mathrm{e}$ \\
\hline FD-CAS FRE & $4.9 \pm 0.1 \mathrm{a}$ & $0.5 \pm 0.1 \mathrm{a}$ & $2.3 \pm 0.1 \mathrm{a}$ & $1.5 \pm 0.1 \mathrm{a}$ & $0.6 \pm 0.0 \mathrm{bc}$ & $4.3 \pm 0.3 \mathrm{ab}$ & $780 \pm 18 \mathrm{~d}$ \\
\hline FD-CAS ENC & $4.9 \pm 0.1 \mathrm{a}$ & $0.5 \pm 0.1 \mathrm{a}$ & $2.4 \pm 0.1 \mathrm{ab}$ & $1.4 \pm 0.1 \mathrm{a}$ & $0.7 \pm 0.0 \mathrm{c}$ & $5.1 \pm 0.2 \mathrm{bc}$ & $737 \pm 22 \mathrm{~cd}$ \\
\hline SD-CAS FRE & $5.0 \pm 0.1 \mathrm{a}$ & $0.5 \pm 0.1 \mathrm{a}$ & $2.6 \pm 0.1 \mathrm{ab}$ & $1.4 \pm 0.1 \mathrm{a}$ & $0.5 \pm 0.0 \mathrm{ab}$ & $6.2 \pm 0.6 \mathrm{c}$ & $650 \pm 13 \mathrm{a}$ \\
\hline SD-CAS ENC & $4.9 \pm 0.1 \mathrm{a}$ & $0.5 \pm 0.1 \mathrm{a}$ & $2.5 \pm 0.1 \mathrm{ab}$ & $1.3 \pm 0.1 \mathrm{a}$ & $0.6 \pm 0.0 \mathrm{bc}$ & $3.9 \pm 0.2 \mathrm{ab}$ & $680 \pm 16 a b$ \\
\hline FD-MD FRE & $5.4 \pm 0.1 \mathrm{~b}$ & $0.7 \pm 0.0 \mathrm{ab}$ & $2.9 \pm 0.1 \mathrm{c}$ & $1.4 \pm 0.1 \mathrm{a}$ & $0.4 \pm 0.1 \mathrm{a}$ & $13.6 \pm 0.7 \mathrm{e}$ & $631 \pm 18$ a \\
\hline FD-MD ENC & $4.9 \pm 0.1 \mathrm{a}$ & $0.8 \pm 0.1 \mathrm{~b}$ & $2.3 \pm 0.2 \mathrm{a}$ & $1.3 \pm 0.1 \mathrm{a}$ & $0.5 \pm 0.0 \mathrm{ab}$ & $5.2 \pm 0.6 \mathrm{bc}$ & $725 \pm 22 \mathrm{bc}$ \\
\hline SD-MD FRE & $5.1 \pm 0.1 \mathrm{a}$ & $0.7 \pm 0.1 \mathrm{ab}$ & $2.7 \pm 0.1 \mathrm{ab}$ & $1.3 \pm 0.0 \mathrm{a}$ & $0.4 \pm 0.0 \mathrm{a}$ & $10.4 \pm 0.8 \mathrm{~d}$ & $672 \pm 16 \mathrm{a}$ \\
\hline SD-MD ENC & $5.1 \pm 0.1 \mathrm{a}$ & $0.7 \pm 0.1 \mathrm{ab}$ & $2.4 \pm 0.0 \mathrm{ab}$ & $1.4 \pm 0.1 \mathrm{a}$ & $0.6 \pm 0.0 \mathrm{bc}$ & $3.6 \pm 0.3 \mathrm{a}$ & $740 \pm 25 \mathrm{~cd}$ \\
\hline
\end{tabular}

FRE, free oil fraction; ENC, encapsulated oil fraction PC, polar compounds; TGO, triacylglycerol oligomers; TGD, triacylglycerol dimers; oxTGM, oxidised triacylglycerol monomers; DAG, diacylglycerols, FFA*, free fatty acids and other polar minor oil components; PV, peroxide value; Toc, tocopherols. Results are expressed as mean \pm standard deviation $(n=3)$. Different letters for each determination denote significant differences $(\mathrm{P}<0.05)$. For sample nomenclature see Table 1. 
Table 3 Oxidative changes in the sunflower oil during storage at $30^{\circ} \mathrm{C}$ in the dark.

\begin{tabular}{lllll}
\hline Time (Days) & Toc $(\mathbf{m g} / \mathbf{k g})$ & Pol $(\mathbf{w t} \%)$ & oxTGM $(\mathbf{w t} \%)$ & PV (meq O $/ \mathbf{k g})$ \\
\hline 0 & $891 \pm 12$ & $0.6 \pm 0.1$ & $0.60 \pm 0.04$ & $3.0 \pm 0.1$ \\
9 & $891 \pm 9$ & $0.6 \pm 0.1$ & $1.8 \pm 0.1$ & $15.0 \pm 1.1$ \\
15 & $862 \pm 22$ & $0.6 \pm 0.1$ & $2.9 \pm 0.1$ & $51.0 \pm 3.3$ \\
20 & $781 \pm 23$ & $0.6 \pm 0.1$ & $4.3 \pm 0.1$ & $104 \pm 6$ \\
22 & $777 \pm 16$ & $0.7 \pm 0.1$ & $5.3 \pm 0.2$ & $114 \pm 6$ \\
32 & $709 \pm 14$ & $0.7 \pm 0.1$ & $8.0 \pm 0.4$ & $181 \pm 7$ \\
36 & $588 \pm 18$ & $0.9 \pm 0.1$ & $10.2 \pm 0.6$ & $226 \pm 10$ \\
43 & $510 \pm 13$ & $1.1 \pm 0.1$ & $11.1 \pm 0.4$ & $265 \pm 11$ \\
49 & $339 \pm 10$ & $1.1 \pm 0.1$ & $13.2 \pm 0.6$ & $305 \pm 11$ \\
55 & $314 \pm 6$ & $1.1 \pm 0.1$ & $14.9 \pm 0.3$ & $351 \pm 14$ \\
60 & $249 \pm 4$ & $1.3 \pm 0.1$ & $17.0 \pm 0.5$ & $367 \pm 17$ \\
65 & $14.3 \pm 0.4$ & $1.6 \pm 0.1$ & $17.8 \pm 0.3$ & $435 \pm 22$ \\
75 & 0 & $3.0 \pm 0.2$ & $28.0 \pm 0.6$ & $500 \pm 25$ \\
84 & 0 & $4.7 \pm 0.2$ & $32.0 \pm 0.8$ & $650 \pm 26$ \\
89 & 0 & $8.5 \pm 0.3$ & $34.0 \pm 1.0$ & $700 \pm 35$ \\
100 & 0 & $19.5 \pm 0.9$ & $42.0 \pm 1.7$ & $1202 \pm 36$ \\
\hline
\end{tabular}

Toc, tocopherols; Pol, polymers (sum of triacylglycerol oligomers and triacylglycerol dimers); oxTGM, oxidised triacylglycerol monomers; PV, peroxide value. Results are expressed as mean \pm standard deviation $(n=3)$. 
Table 4 Oxidation time periods at which tocopherols were completely depleted and when the $\mathrm{PV}$ reached $100 \mathrm{meq} / \mathrm{kg}$ oil.

\begin{tabular}{|c|c|c|c|c|}
\hline \multirow{2}{*}{ Sample } & \multicolumn{2}{|c|}{ Time ${ }_{\text {Toc }=0}(\mathrm{~d})$} & \multicolumn{2}{|c|}{ Time $P V=100(d)$} \\
\hline & FREE & ENCAPSULATED & FREE & ENCAPSULATED \\
\hline FD-CAS & $131-145$ & $145-153$ & 35 & 35 \\
\hline SD-CAS & $105-117$ & $190-200$ & $44-49$ & $70-82$ \\
\hline FD-MD & $73-79$ & $112-127$ & $21-25$ & $49-59$ \\
\hline SD-MD & $79-87$ & $120-130$ & $<7$ & $49-59$ \\
\hline
\end{tabular}




\section{Figure legends}

Figure 1 Oxidation of the free (FRE) and encapsulated (ENC) oil fractions in the CAS (a-c) and MD ('-'-c') samples obtained by freeze-drying (FD) or spray-drying (SD). The samples were oxidised at $30{ }^{\circ} \mathrm{C}$ in the dark and $0.0 \% \mathrm{RH}$. Data correspond to mean values and the error bars show the standard deviation $(n=3)$. 

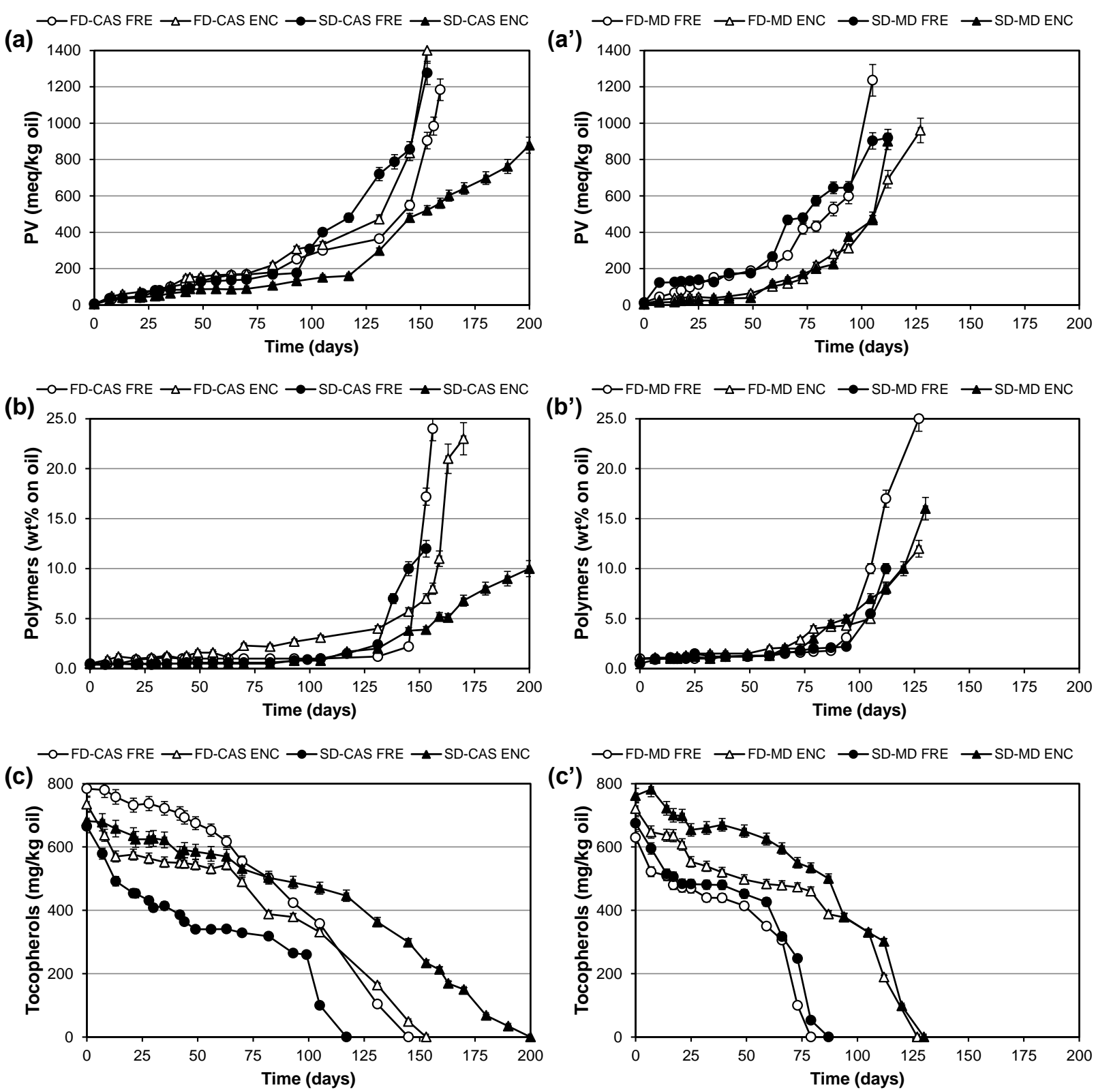

Figure 1 